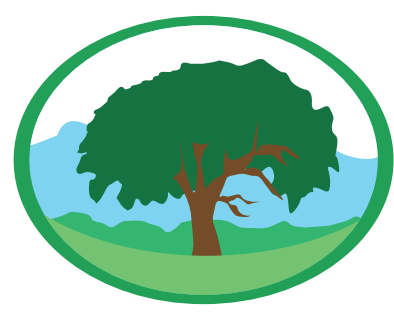

\title{
VIABILIDADE DA BORRA DE TINTA NA APLICAÇÃO DA TÉCNICA DE COPROCESSAMENTO EM FORNOS DE CIMENTÓ
}

\author{
BARBOSA, F. A. T.'; CRIPPA, L. B. ${ }^{2}$. \\ ${ }^{1 B}$ Biomédico Analista Ambiental - Centro Universitário da Serra Gaúcha - FSG - francis_atbarbosalahotmail.com \\ ${ }^{2}$ Mestre em Biologia - Universidade do Vale do Rio dos Sinos - UNISINOS, Docente no curso de Biomedicina - Centro \\ Universitário da Serra Gaúcha - FSG - liziane.crippa2@ifsg.br
}

Palavras-chave: resíduos sólidos, indústria de tintas, gerenciamento de resíduos.

\section{Resumo}

As tintas estão cada vez mais sendo aplicadas em várias atividades e sendo desenvolvidas para que se tornem menos poluentes ao meio ambiente. Um dos principais desafios ambientais é a destinação adequada destes resíduos. Foi realizado um estudo sobre a aceitabilidade de amostras de borras de tintas de três tipos de indústrias na técnica de coprocessamento em fornos de cimento. 0 estudo apresentou que $77 \%$ das amostras estavam aptas para coprocessamento de acordo com a licença de operação para empresas de blendagem emitida pela FEPAM - Fundação Estadual de Proteção Ambiental Henrique Luiz Roessler do Rio Grande do Sul. Portanto permite uso mais nobre do material que não o envio a aterro sanitário ou até mesmo locais inapropriados que representa um ganho principalmente para o meio ambiente.

\section{VIABILITY FROM PAINT DREGS IN THE IMPLEMENTATION OF CO-PROCESSING TECHNIQUE IN CEMENT KILNS}

Keywords: solid waste, painting industry, waste management.

\begin{abstract}
The paints are increasingly being applied in various activities and being developed to become less polluting to the environment. One of the main environmental challenges is the proper disposal of these wastes. A study of the acceptability of paint dregs samples of three types of industries in the coprocessing technique in cement kilns has been performed. The study showed that $77 \%$ of the samples were suitable for coprocessing according to the operating license for blending companies issued by FEPAM - State Foundation for Environmental Protection Henrique Luiz Roessler of Rio Grande do Sul. It therefore allows for a more noble use of material other than landfill or even in inappropriate places which represents a gain primarily for the environment.
\end{abstract}




\section{INTRODUÇÃO}

A evolução das tendências mundiais no ramo das tintas é muito grande, cada vez mais estão sendo aplicadas em inúmeras atividades, como na pintura artística, automotiva, entre outras atividades em que este composto está sendo inserido. Dia a dia novas cores estão sendo desenvolvidas e novas tecnologias estão sendo aplicadas para que estes compostos se tornem menos poluentes ao meio ambiente e principalmente para diminuir os riscos de quem manuseia (Da Silva et al., 2004).

Um dos principais desafios ambientais das indústrias e das residências dos brasileiros é a destinação adequada dos resíduos sólidos, que no decorrer dos anos esta situação vem se agravando muito, principalmente pela disposição inadequada de compostos perigosos no solo. O Brasil está entre os países que fazem uso da reciclagem de resíduos, porém, nem sempre a mesma é feita de maneira correta. Estima-se que de 30\% a 50\% dos resíduos sequer são coletados das ruas ou separados para sua reciclagem (Rocha et al., 2011).

As empresas brasileiras têm obrigação legal, sendo responsáveis pelos seus resíduos que atualmente são colocados em aterros sanitários e isso faz com que alternativas sejam encontradas, e uma delas é a técnica de coprocessamento em fornos de cimento (Milanez et al., 2009). O resíduo de borra de tinta é um composto altamente comburente e por isso deve ser melhor aproveitado do que encaminhado a aterro sanitário, a recuperação da energia contida neste resíduo contribui para a conservação de matéria prima não renovável, reduzindo os custos de fabricação (Mello \& Suares, 2012).

Uma das principais vantagens é a sua destruição total pelas altas temperaturas dentro dos fornos de cimento utilizados no coprocessamento e a retenção das cinzas no próprio forno, sendo incorporado no cimento bruto, sem fumaça, em um sistema fechado (Freitas \& Nóbrega, 2014). O coprocessamento apresenta bons resultados, pois todas as partes envolvidas são beneficiadas (Gautam et al.,2010).

A natureza é beneficiada com uma diminuição da sua exploração das reservas naturais, a população com a preservação ambiental e a manutenção das matas, do ar e dos córregos e a empresa produtora de cimento através da economia de combustível e menor matéria prima consumida (Rocha et al., 2011). Atualmente, não se tem muitos dados de estudos empregando a borra de tinta que é amplamente utilizada em diversos segmentos da indústria. Frente a isso, o presente trabalho avalia a viabilidade do uso da borra de tinta na técnica de coprocessamento em fornos de cimento, como alternativa para o reaproveitamento deste resíduo.

\section{MATERIAL E MÉTODOS}

2.1 Características do local e das amostras

O estudo experimental foi realizado no munícipio de Farroupilha na Serra Gaúcha, no estado do Rio Grande do Sul, entre janeiro de 2015 e maio de 2016. Foram inclusas no estudo as amostras de borras de tintas de três áreas específicas: indústria automotiva, indústria metalúrgica e indústria de plásticos.

O estudo avaliou 150 amostras de borras de tintas, dividas em 50 amostras para cada área específica. Em algumas amostras foi realizado um processamento delas antes das análises, pois se apresentavam sólidas ou semissólidas.

Tanto as análises físico químicas como as análises de metais foram realizadas no próprio laboratório da empresa de blendagem, onde as coletas foram realizadas e os valores analisados segundo a licença de operação vigente do órgão fiscalizador do Rio Grande do Sul e as normas da cimenteira licenciada para a técnica de coprocessamento.

2.2 Análises físico químicas e análise de metais

$\mathrm{O}$ estudo teve como base as análises físico químicas utilizadas na técnica de coprocessamento: radioatividade, poder calorífico, $\mathrm{pH}$, umidade, cinzas, íons cloreto e análises de metais, conforme Tabela 1 . Posteriormente, foram analisadas 10 amostras de blend final utilizando as borras de tintas aprovadas para coprocessamento em sua composição, comparando os resultados obtidos com os limites para uso no coprocessamento, através da licença de operação emitida pela FEPAM. 
Tabela 1 - Parâmetros utilizados na metodologia das análises

\begin{tabular}{|c|c|}
\hline Parâmetros & Resultados \\
\hline Radioatividade (msv.hr $\left.{ }^{-1}\right)$ & Contador Geiger \\
\hline $\mathrm{pH}$ & Charles Black \\
\hline Umidade (\%) & NBR 10664/1989 \\
\hline Cinzas (\%) & NBR 10664/1989 \\
\hline Poder Calorífico Inferior & DIN 51900-1 \\
\hline \multicolumn{2}{|l|}{$\left(\right.$ Kcal.kg $\left.^{-1}\right)$} \\
\hline Íon Cloreto (\%) & EPA 5050 \\
\hline Digestão Ácida & EPA 3051A/3052/3050B \\
\hline Cádmio - Cd (mg.kg-1) & Standard Methods 3120 \\
\hline \multicolumn{2}{|c|}{$A$ e B } \\
\hline Mercúrio - Hg $\left(\mathrm{mg} \cdot \mathrm{kg}^{-1}\right)$ & Standard Methods 3120 \\
\hline \multicolumn{2}{|c|}{ A e B } \\
\hline Tálio - TI (mg.kg-1) & Standard Methods 3120 \\
\hline \multicolumn{2}{|c|}{ A e B } \\
\hline Arsênio - As (mg.kg-1) & Standard Methods 3120 \\
\hline \multicolumn{2}{|c|}{ A e B } \\
\hline Cobalto - Co (mg.kg-1) & Standard Methods 3120 \\
\hline \multicolumn{2}{|c|}{$A$ e B } \\
\hline Níquel - Ni (mg.kg-1) & Standard Methods 3120 \\
\hline \multicolumn{2}{|c|}{$A$ e B } \\
\hline Telúrio - Te (mg.kg-1) & Standard Methods 3120 \\
\hline \multicolumn{2}{|c|}{ A e B } \\
\hline Cromo - Cr (mg.kg-1) & Standard Methods 3120 \\
\hline \multicolumn{2}{|c|}{ A e B } \\
\hline Chumbo - Pb (mg.kg-1) & Standard Methods 3120 \\
\hline \multicolumn{2}{|c|}{$A$ e B } \\
\hline
\end{tabular}

\subsubsection{Determinação de Radioatividade e $\mathrm{pH}$}

Foi realizado a análise de radioatividade, que consiste, em determinar se a amostra possui caráter radioativo, pois amostras radioativas não podem ser aceitas na técnica de coprocessamento. Está análise foi realizada através do medidor Geiger em contato com a amostra.

As que apresentaram índices de radioatividade maiores que 50 microsieverts por hora foram consideradas radioativas e descartadas da utilização no estudo. A análise de $\mathrm{pH}$ consiste em determinar o potencial de hidrogênio das amostras.

Para analisar o $\mathrm{pH}$ tornou-se a amostra líquida para que a mesma possa entrar em contato com eletrodo de leitura do hidrogênio e quantificar o $\mathrm{pH}$. $\mathrm{O}$ método consistiu em pesar 20 gramas da amostra e acrescentar $20 \mathrm{~mL}$ de água deionizada.

$\mathrm{O}$ equipamento mede escala de 0 a 14 que converte o valor em unidades de $\mathrm{pH}$ (Charles Black - Methods of Soil Analysis).

2.2.2 Determinação de Umidade, Cinzas e Poder Calorífico

A determinação de umidade consistiu em colocar a amostra em estufa de secagem Tecnal, à uma temperatura de $105^{\circ} \mathrm{C}$ por 60 minutos (NBR 10664/1989). A determinação de cinzas consiste em quantificar as cinzas das amostras.

O resíduo obtido na determinação de sólidos totais é submetido à calcinação a $800^{\circ} \mathrm{C}$ por 60 minutos no forno mufla. $\mathrm{O}$ material restante desta queima representa as cinzas (NBR 10664/1989).

A análise do poder calorífico consiste num dispositivo para determinar o calor de combustão de compostos. O resultado das amostras representa o seu potencial energético, porém esse valor é dado em poder calorifico superior (PCS), que consiste na soma da energia liberada na forma de calor e da energia gasta na vaporização da água na queima.

Para uso em coprocessamento se utiliza o poder calorifico inferior (PCI), que é somente a energia liberada na forma de calor, obtida pela divisão do PCS por 1,08 (DIN 51900-1).

2.2.3 Determinação de íons seletivos, digestão ácida e análise dos metais

A determinação de íons seletivos é um procedimento que tem por objetivo recuperar os íons da queima na bomba calorimétrica. Neste caso o equipamento de íons seletivo possui eletrodos específicos para cada íon, no estudo utilizado para cloreto, fluoreto e cianeto.

A leitura consiste em avolumar uma solução absorvedora, utilizando uma mistura de bicarbonato e carbonato de sódio, juntamente com a queima da bomba calorimétrica da amostra escolhida, para ter função de absorver os íons liberados na queima dentro 
da bomba, após este processo coloca-se a solução padrão do íon selecionado e ler no medidor de íons, o resultado obtido (em porcentagem - \%). Sendo que, o cloreto é fator de exclusão de recebimento na cimenteira, pois o cloro elevado prejudica o funcionamento do forno rotativo de cimento (EPA 5050).

As amostras nem sempre são líquidas e para análise de metais devem ser. Para tanto foi realizada digestão ácida por meio de ácido nítrico, ácido clorídrico e peróxido de hidrogênio em uma chapa aquecedora, afim de tornar a amostra liquida para a sua leitura no ICP-OES (EPA 3051A/3052/3050B).

A mais complexa análise é a de metais, que consiste em determinar a concentraçáo presente nos extratos aquosos, provenientes da digestão ácida das amostras. A análise de metais é realizada através do equipamento de espectrometria de emissão ótica por plasma indutivamente acoplado ou ICP - OES.

O princípio básico da análise é relativamente simples, as amostras são introduzidas em um plasma de argônio a uma temperatura de aproximadamente $7727 \mathrm{C}^{\circ}$, na forma de uma névoa finamente dispersa, a qual é vaporizada. Ao longo do trajeto no plasma, ocorre dissociação e ionizaçáo.

Os íons formados são retirados do plasma através de uma interface onde são separados em relação às suas razóes massa/carga e, então, detectados por um multiplicador de elétrons. Assim obtendo o resultado de diversos metais, no estudo foram analisados somente os classificatórios para aceitabilidade na técnica de coprocessamento: cádmio, mercúrio, tálio, arsênio, cobalto, níquel, telúrio, cromo e chumbo (Standard Methods 3120 A e B).

\section{RESULTADOS E DISCUSSÃO}

Dentre os parâmetros analisados, visando a licença de operação para unidades de blendagem, emitida pela FEPAM, não foram encontradas amostras com caráter radioativo. A média do $\mathrm{pH}$ das 150 amostras ficou em 7,24, representando caráter neutro.

Pode-se observar que no setor de indústrias automotivas, das 50 amostras de borra de tinta analisadas, 70\% estavam aptas para aceitação na técnica de coprocessamento, com resultados dentro dos limites permitidos para o uso na técnica de coprocessamento de resíduos em fornos de cimento - FEPAM, conforme a Figura 1. No setor de indústrias metalúrgicas de um total de 50 amostras analisadas, o estudo apresenta uma aprovação de $74 \%$ com resultados dentro dos limites aceitos. Neste setor os metais tóxicos apresentaram valores fora do padrão.

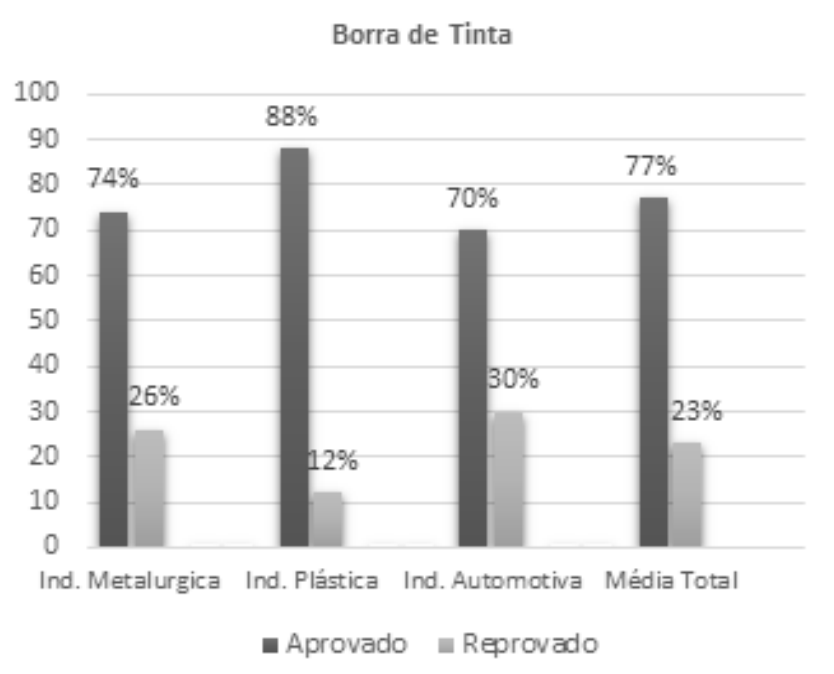

Figura 1. Porcentagem de amostras aprovadas e reprovadas referente aos parâmetros da FEPAM, divididas em setores da indústria

O setor de indústrias de plásticos foi o que obteve a maior aprovação em relação aos demais, com 88\% das amostras aptas para o coprocessamento em fornos de cimento com seus resultados dentro dos limites determinados. As amostras reprovadas apresentaram o poder calorífico abaixo do mínimo exigido, principalmente por sua composição a base água, o que a torna com menos poder de queima.

A média total de amostras, com os três setores em conjunto, apresentaram $77 \%$ aptas para coprocessamento nos fornos de cimento dentro dos limites exigidos na licença de operação e apenas $23 \%$ foram reprovadas para a técnica de coprocessamento em fornos de cimento.

Dentre as análises realizadas, pode-se destacar os parâmetros que são classificatórios para a sua aplicação na técnica de coprocessamento, que é a determinação do poder calorífico ou poder energético, e a 
determinação da quantidade de metais presentes nas amostras de borras de tintas. Das 150 amostras totais, 145 obtiveram o poder calorífico inferior (PCI) acima dos limites mínimos exigidos pela licença de operação de empresas de blendagem emitida pela FEPAM que é de $1620 \mathrm{kcal}^{\mathrm{kg}}{ }^{-1}$, conforme Tabela 2 .

$\mathrm{O}$ resultado indica, que a borra de tinta pode ser um excelente substituinte térmico para este processo. Das amostras avaliadas $120(80 \%)$ obtiveram o resultado de íons cloreto abaixo de $0,5 \%$.

Tabela 2 - Limites da FEPAM nas amostras para coprocessamento

\begin{tabular}{cc}
\hline Parâmetros & Resultados \\
PCI - Poder Calorífico & $>1620 \mathrm{kcal} \cdot \mathrm{kg}^{-1}$ \\
Inferior & \\
$\mathrm{Hg}$ - Mercúrio & $<10 \mathrm{mg} \cdot \mathrm{kg}^{-1}$ \\
$\mathrm{Cr}$ - Cromo & $<3000 \mathrm{mg} \cdot \mathrm{kg}^{-1}$ \\
$\mathrm{~Pb}-$ Chumbo & $<2000 \mathrm{mg} \cdot \mathrm{kg}^{-1}$ \\
$\mathrm{Cd}+\mathrm{Ti}-$ Cádmio & $<100 \mathrm{mg} \cdot \mathrm{kg}^{-1}$ \\
Tálio & \\
As + Co $+\mathrm{Ni}+\mathrm{Te}-$ & $<3000 \mathrm{mg} \cdot \mathrm{kg}^{-1}$ \\
Arsênio + Cobalto + Níquel & \\
+ Telúrio &
\end{tabular}

Das 34 amostras reprovadas para a técnica de coprocessamento, como representadas na Figura 2, 15 foram da indústria automotiva, 13 da metalúrgica e 6 da indústria de plásticos. Destas, 7 apresentaram o somatório de arsênio, cobalto, níquel e telúrio acima do limite máximo permitido, representando $21 \%$ dos casos de reprovação.

O valo obtido da soma do cádmio e tálio apresentaram 15 amostras acima do permitido, totalizando $44 \%$ reprovadas. Esse somatório foi o segundo maior índice de reprovação entre os metais, aparecendo em todos os setores escolhidos no estudo.

O chumbo se apresentou elevado em mais da metade das amostras reprovadas, em um total de 19 amostras, ou seja, 56\% dos casos reprovados, assim mostrando um grande percentual de chumbo, principalmente nas borras de tintas provenientes da indústria automotiva, pois são utilizadas tintas com mais metais na técnica de pintura automotiva.

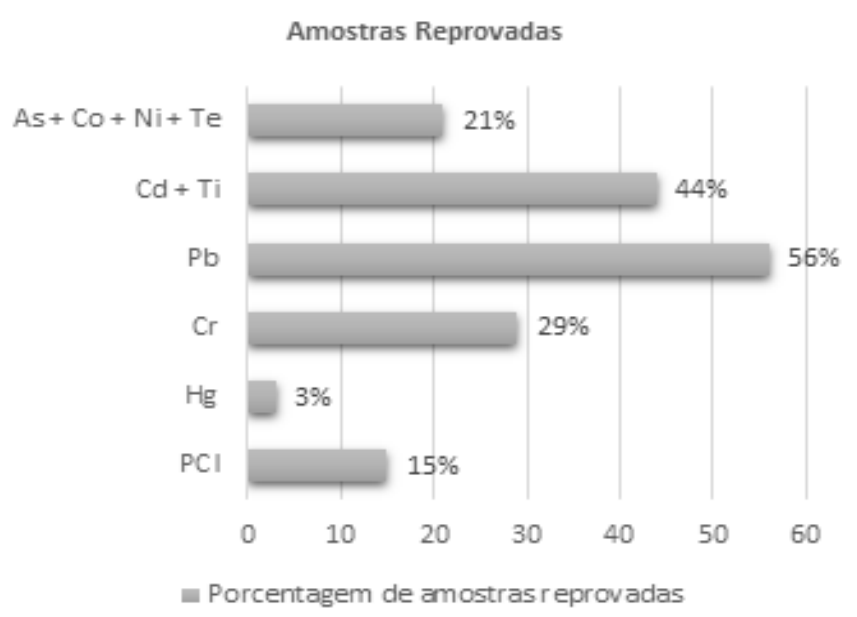

Figura 2. Porcentagem de amostras de borra de tinta reprovadas nos limites da FEPAM

O cromo apareceu em 10 amostras acima dos limites para o coprocessamento, representando $29 \%$ dos casos de reprovação. $\mathrm{O}$ mercúrio apareceu elevado em apenas uma amostra, representando 3\% do total de reprovações e o poder calorífico inferior em apenas 5 amostras, representando um total de $15 \%$ das amostras reprovadas.

Pelas características apresentadas, o resíduo da borra de tinta é classificado como resíduo perigoso - classe 1, o que reflete no processo do resíduo, pois têm um cuidado a mais em relação à segurança no transporte, armazenamento e principalmente no manuseio. $\mathrm{O}$ material final da blendagem de resíduos é chamado de blend final e consiste no material pronto para substituir os combustíveis na fabricação de cimento nos fornos rotativos.

Tabela 3 - Limites do blend final para coprocessamento na cimenteira*

\begin{tabular}{cc}
\hline Parâmetros & Resultados \\
PCS - Poder Calorífico & $>3500{\mathrm{kcal} . \mathrm{kg}^{-1}}^{\text {Superior }}$ \\
Umidade & $<15 \%$ \\
Cinzas & $<20 \%$ \\
Cl - Cloro & $<0,5 \%$ \\
$*$ Limites adotados pela fábrica de cimento responsável pelos \\
fornos de coprocessamento, seguindo os limites exigidos na CONAMA \\
$264 / 99$
\end{tabular}


Para isso ele deve apresentar algumas características, conforme apresenta a Tabela 3, como limite mínimo de poder calorífico de $3500 \mathrm{kcal} . \mathrm{kg}^{-1}$, teores de umidade e cinzas em torno de 15 a $20 \%$ e principalmente o cloreto, inferior a $0,5 \%$, principalmente por prejudicar a funcionalidade dos fornos rotativos e em altas quantidades pode gerar problemas para a fabricação do cimento, a integridade do processo e a segurança da planta cimenteira.

As amostras analisadas que foram aceitas para coprocessamento foram implementadas na blendagem juntamente com outros resíduos diversos, formando o blend final, que é o enviado a cimenteira para sua queima nos fornos de clínquer e implementação ao cimento, sendo assim sua completa destruição térmica.

Tabela 4 - Análises do blend final em que a borra de tinta foi inserida

\begin{tabular}{crrrr}
\hline Amostras & \multicolumn{1}{l}{$\begin{array}{l}\text { Cinzas } \\
\text { \% }\end{array}$} & $\begin{array}{l}\text { Umidade } \\
\text { \% }\end{array}$ & $\begin{array}{l}\text { PCS } \\
\text { kcal/kg }\end{array}$ & \multicolumn{2}{l}{ Cloretos } \\
01 & 10,49 & 13,74 & 6673 & 0,2605 \\
02 & 11,61 & 12,58 & 4187 & 0,1403 \\
03 & 14,32 & 14,61 & 4306 & 0,1684 \\
04 & 15,11 & 11,87 & 4335 & 0,1883 \\
05 & 17,15 & 12,38 & 4400 & 0,1776 \\
06 & 19,01 & 13,28 & 3954 & 0,1446 \\
07 & 16,81 & 10,71 & 4783 & 0,2117 \\
08 & 16,18 & 11,24 & 4415 & 0,1994 \\
09 & 18,85 & 12,01 & 5403 & 0,2014 \\
10 & 16,86 & 11,22 & 4894 & 0,2151
\end{tabular}

Os resultados das 10 amostras aprovadas, conforme apresentadas na Tabela 4, mostram que o menor poder calorífico encontrado foi de $3954 \mathrm{kcal} . \mathrm{kg}^{-1}$, ou seja, o menor valor encontrado está acima do limite mínimo que é de $3500 \mathrm{kcal} \cdot \mathrm{kg}^{-1}$. Em relação ao teor de cinzas, todos os valores foram menores que $20 \%$, que é o limite estabelecido pela cimenteira.

$\mathrm{O}$ teor de umidade apresentou valores inferior a $15 \%$, se mostrando uma mistura de ótima qualidade. $\mathrm{O}$ maior resultado de cloro encontrado foi de $0,26 \%$, onde o limite é de $0,5 \%$, representando um resultado ótimo para coprocessamento e para a cimenteira que receberá este composto de diferentes resíduos onde os valores indicam que não apresentarão problemas para a qualidade do cimento nem para a estrutura dos fornos rotativos.

Conforme os estudos de Tiwary (2014) sobre coprocessamento na Índia, pode se observar que eles encontraram resultados positivos avaliando o uso de coprocessamento para recuperação energética dos resíduos perigosos como a borra de tinta aqui estudada. Porém nosso estudo concentrou no resíduo de borra de tinta e não a classe inteira dos resíduos perigosos como no estudo deles, mas mesmo assim chegando a resultados bem parecidos quanto a viabilidade do uso no coprocessamento.

Os estudos recentes sobre coprocessamento utilizam mais sobre sua viabilidade visando custos de operação e custos para a cimenteira, e náo propriamente de resíduos inseríveis nesta técnica, principal motivo para a realização deste experimento que obteve resultados promissores. A borra de tinta foi avaliada conforme Gautam (2010) para a técnica de coprocessamento em fornos de cimento na Índia, onde foi classificada como um dos resíduos mais rentáveis para esta técnica de gerenciamento de resíduos, principalmente pela sua excelente viabilidade energética e pela baixa emissão de poluentes ao meio ambiente com a queima, sendo sua composição muito satisfatória na implementação do clínquer de cimento, assim não afetando a qualidade nem o desempenho do cimento produzido.

O presente estudo e o de Gautam (2010) tem como base principal de resultados a de que o coprocessamento é a melhor opção para esse resíduo perigoso em relação a incineração e aterros sanitários, principalmente pelo fato do seu potencial energético onde sua ida a aterros sanitários é um desperdício de energia. Desta forma, apresenta vantagens seu emprego, tanto para a empresa geradora do material quanto para a empresa blendadora e principalmente uma segurança e tranquilidade para a cimenteira licenciada que fara a queima dos resíduos.

As informaçóes analisadas demonstram que os resíduos de borras de tintas, continuarão sendo gerados nestas indústrias, e ao longo do tempo, necessitando de alternativas, não apenas de tratamentos e destinaçóes temporárias, mas, em definitivo, com emprego no coprocessamento em fornos de cimento onde o resíduo de borra de tinta apresentou resultados promissores para ser implementado a outros compostos. 


\section{CONCLUSÃO}

A partir do estudo e levantamento de informaçóes sobre a utilização do resíduo de tinta de diferentes seguimentos da indústria em substituição de combustíveis não renováveis no coprocessamento em fornos de cimento, se percebe a viabilidade técnica dentro do processo da fabricação do cimento. Considerando a geração constante deste resíduo, a sua compatibilidade de elementos físicos e químicos com as matérias-primas utilizadas no processo de fabricação do cimento, transformando a mistura do resíduo de tinta altamente energética em um combustível alternativo.

A aplicação da técnica de coprocessamento com o resíduo de borra de tinta, dentro dos padróes legais, é considerada adequada às necessidades operacionais do forno de cimento, onde, através desta técnica, se constata que a disposição deste resíduo em aterro sanitário, somente adiaria o tratamento do passivo, não utilizando seu potencial energético. Os resultados obtidos nas análises de aceitabilidade das amostras para a técnica de coprocessamento mostraram-se satisfatórios tanto para o seu recebimento, como para a sua mistura no blend final, pois apresentou características dentro das normas estabelecidas pela fiscalização ambiental e pela cimenteira licenciada, na maioria das amostras.

Portanto o estudo teve a constataçáo de que o coprocessamento utilizando o resíduo de borra de tinta é considerado uma alternativa para as empresas envolvidas, onde os benefícios socioambientais são evidentes e podem ser definitivos, uma vez que serão incorporados ao produto final, que é o cimento. Pois conforme as análises, o material final encaminhado a cimenteira está apto, dentro das normas e com uma excelente combustão acima do limite mínimo para esse tipo de resíduo.

\section{LITERATURA CITADA}

APHA. Standard Methods for the Examination of Water and Wastewater, American Public Health Association, 21st Edition, EUA, 2012. 3120 A e B, p. 3-38, 3-39, 3-40.

ASSOCIAÇÃO BRASILEIRA DE NORMAS TÉCNICAS ABNT. NBR 10664: Determinação de Sólidos totais, Sólidos suspensos e Sólidos dissolvidos - Método de gravimetria. Rio de Janeiro: ABNT, Rio de Janeiro, 1989, 7 p.
BERNARDO, A. C. S. M.; CARPIO, R. C.; SILVA, R. J. Otimização multi-objetivos da produção de cimento Portland com co-processamento e adição de mineralizadores. SIMPÓSIO DE MEC NICA COMPUTACIONAL - SMC, IX, 2010, São João Del Rei. In. Anais do IX Simpósio da Associação Brasileira de Métodos Computacionais em Engenharia. São João Del Rei: 2010 .

BLACK, C. A.; Methods of Soil Analysis; American Society of Agronomy: Madison, WI, EUA, 1973, 780 p.

CONAMA n 264, de 26 de agosto de 1999 - Conselho Nacional do Meio Ambiente, 1999. Publicado no Diário Oficial da União no 54, pag. 80-83, 2000. Disponível em: <http://www.mma.gov. $\mathrm{br} /$ port/conama/legiabre.cfm? codlegi=262>. Acesso em: Abril de 2016.

DA SILVA, M. R. A.; DE OLIVEIRA, M. C.; NOGUEIRA R. F. P. Estudo da aplicação do processo foto-fenton solar na degradação de efluentes de indústria de tintas. Revista Eclética Química, v. 29, n. 2, p. 19-26, 2004.

DIN 51900-1, Determining the gross calorific value of solid and liquid fuels using the bomb calorimeter, and calculation of net calorific value. DIN - Deutsches Institut fur Normung e V. Beuth Verlag GmbH, Berlin, Germany, 2000.

EMBRAPA - Empresa Brasileira de Pesquisa Agropecuária. Manual de métodos de análise de solo; Centro Nacional de Pesquisa de Solos; Minstério de Agricultura e do Abastecimento, Rio de Janeiro, EMBRAPA, Revista Atual, p. 1-212, 2, 1997.

FEAM - Fundação Estadual do Meio Ambiente. Análise técnica e ambiental da utilização de resíduos sólidos urbanos na produção de cimento (Coprocessamento). Fundação Estadual do Meio Ambiente, Belo Horizonte, Feam, p. 1-38, 2010.

FREITAS, S. S.; NÓBREGA, C. C. Os benefícios do coprocessamento de pneus inservíveis para a indústria cimenteira. Revista Engenharia Sanitária Ambiental, v. 19, n. 3, p. 293-300, 2014.

GAUTAM, S. P.; BUNDELA, P. S.; MURUMKAR, M. Paint sludge waste co-processing at the ACC Wadi Cement Works in Karnataka, India. WIT Transactions on Ecology and the Environment, v. 140, n. 5, p. 57-66, 2010.

KIHARA, Y. Co-processamento de resíduos em fornos de cimento: tendências. SEMINÁRIO DE DESENVOLVIMENTO SUSTENTÁVEL E A RECICLAGEM NA CONSTRUÇÃO CIVIL, II, 1999, São Paulo. In. Anais do II seminário de desenvolvimento sustentável e a reciclagem na construçáo civil. São Paulo: IBRACON, 1999.

MANTEGAZZA, E. Aspectos ambientais do coprocessamento de resíduos em fornos de produção de clínquer no estado de São Paulo. São Carlos: USP, 2004. Dissertação (Mestrado em Engenharia Mecânica) Escola de Engenharia de São Carlos, Universidade de São Paulo, São Carlos, 2004. 
MARCIANO, J. E.; KIHARA, Y.; ESPER, M. W. A questão ambiental no setor cimenteiro. CONGRESSO BRASILEIRO DE CIMENTO, IV, 1996, São Paulo. In. Anais do IV Congresso Brasileiro de cimento. São Paulo: ABCP, 1996.

MELLO, V. M.; SUAREZ, P. A. Z. As formulaçôes de tintas expressivas através da história. Revista Virtual de Química, v. 4, n.1, p. 2-12, 2012.

MILANEZ, B.; FERNANDES, L. DE O.; PORTO, M. F. DE S. A coincineraçáo de resíduos em fornos de cimento: riscos para a saúde e o meio ambiente. Revista Ciência e Saúde Coletiva, v. 14, n. 6, p. 2143-2152, 2009.

MOLINARI, M. A.; QUELHAS, O. L. G.; FILHO, A. P. DO N. Avaliação de oportunidades de produção mais limpa para a redução de resíduos sólidos na fabricação de tintas. Revista Produção, v. 23, n. 2, p. 364-374, 2013.

NETTO, Q. M. P.; REIS, A. C. DA C.; NETO, B. J. B. Estudo da logística reversa de pneus, solução econômico-sustentável a partir da produção de asfalto-borracha. Revista Científica do Centro de Estudos em Desenvolvimento Sustentável da UNDB, CEDS, v. 1, n. 5, p. 1-13, 2016.

PRAXEDES, P. Aplicação da Borra de tinta automotiva na produção de cerâmica branca refratária. Curitiba: UFPR, 2013. Dissertação (Mestrado em Engenharia e Ciência dos Materiais) Programa de Pós-Graduação em Engenharia e Ciência dos Materiais, Universidade Federal do Paraná, 2013.

QUEIROZ, F. C. B. P.; HÉKIS, H. R.; QUEIROZ, J. V. A geração de inovação como estratégia de diferenciação: Um estudo com empresas do setor de tintas, vernizes e solventes do sul de Santa Catarina. Revista CPPG - CESUC, v. 13, n. 23, p. 8-23, 2010 .

ROCHA, S. D. F.; LINS, V. F. C.; SANTO, B. C. E. Aspectos do coprocessamento de resíduos em fornos de clínquer. Revista Engenharia Sanitária Ambiental, v. 16, n. 1, p. 1-10, 2011.

TIWARY, A.; SHARMA, G.; GUPTA, P. K. Qantification of the reduced environmental impacts with use of co-processing in cement kilns in India. Journal of Environmental Science, Toxicology and Food Technology, IOSR-JESTFT. ISSN: 23192402, ISSN: 2319-2399. v. 8, n. 3, p 20-30, 2014.

USEPA - United States Environmental Protection Agency. Microwave Assisted Acid digestion of Sediments, Sludges, Soils and Oils, Method 3050, Index to EPA Test Methods SW, EUA, p 846, 1994a.

USEPA - United States Environmental Protection Agency. Microwave Assisted Acid digestion of Sediments, Sludges, Soils and Oils, Method 3051, Index to EPA Test Methods SW, EUA, p 846, 1994 b.

USEPA - United States Environmental Protection Agency. Microwave Assisted Acid digestion of Sediments, Sludges, Soils and Oils, Method 3052, Index to EPA Test Methods SW, EUA, p 846, 1994.

USEPA - United States Environmental Protection Agency. Bomb Preparation Method for Solid Waste, Method 5050, Index to EPA Test Methods SW, EUA, Region I, 2003. 